\title{
How to anticipate psychological suffering
}

\author{
Evelyne Bourquin \\ Centre Hospitalier Universitaire Vaudois, Département de Chirurgie, Service d'ORL, Switzerland. \\ Correspondence: Evelyne Bourquin. Address: Centre Hospitalier Universitaire Vaudois, Département de Chirurgie, \\ Service d'ORL, Switzerland. Email: Evelyne.Bourquin@chuv.ch
}

Received: June 12, 2013

Accepted: October 31, $2013 \quad$ Online Published: January 25, 2014

DOI : $10.5430 /$ jnep.v4n4p99

URL: http://dx.doi.org/10.5430/jnep.v4n4p99

\section{Abstract}

The major ENT surgery generates great losses like psychological and social disorders. However, these psychological sufferings are generally obstacle to their physical recovery and their return home in good condition. The objective is to develop a nurse consultation to anticipate these difficulties, which may appear in the critical post-operative phase. This will allow us to improve the care offer and anticipate postoperative problems and better prepare patient and family for the return home. The feedback from patient and caregivers are very positive and the nurse who performs this consultation becomes a key person for the patient. Nurse consultation help diagnose the concerns of patients.

\section{Key words}

Preoperative nurse consultation, Head and neck surgery

\section{Introduction}

At CHUV university hospital in Lausanne, caregivers belonging to the ENT (Ear, Nose and Throat) department welcome patients with ENT cancers. In order to improve the follow-up of the customer care, the ENT department has decided to work in collaboration with the linked psychiatry nursing department.

\section{Major psychological impact after an ENT surgery}

The region of ENT is key to essential functions of life such as breathing, swallowing, speaking and smelling. Following oncological pathologies, some patients undergo a major ENT operation (partial or complete pharyngo- laryngectomy, glossectomy, tumorectomy). The average hospital stay is about 30 days, depending on complications, aftermath of the surgery and its psycho-social factors.

In the post-operative phase patients experience major losses, which can lead to different processes of mourning such as loss of health, loss of voice, decreasing lung function, family role change, social or professional role change. They also face a change of self-image: facial oedema, artificial breathing hole in the neck, secretions (...). The result of this is often the onset of major psychological disorders ${ }^{[1]}$.

Needless to say, the disease, the operation and their consequences lead not only to emotional reaction from the patient, but also complication to their family and social surroundings. However, these psychological sufferings may be an obstacle to their physical recovery and their return home. 
Some patients experience a significant psychic distress in the post-operative phase ${ }^{[2]}$. This is often taken into account too late. One reason is "the inhibition of the clinician who perceives the patient's changes of mood as marginal manifestations and ultimately normal for such an illness" ${ }^{[3]}$. Another reason is that the caregivers focus at first on the technical care.

\section{Complex care situations}

After many particularly complex care cases, we created together with the nursing department PLI a meeting about these situations. The aim was to better understand the difficulties faced by the health care team in its mission to support patients. These meetings gave us the opportunity to compile many observations. We observe that anxiety and depressive states, or reactions, such as withdrawal, aggression or care refusals, were often an expression of psychic pain experienced by the patient who suffered from ENT surgery, e.g. complete laryngectomy, glossectomy.

In addition, we found that a number of psychological and social problems had not been previously identified and lead to crises during hospitalisation. This was blatant during the preparation for the return home and resulted in the prolongation of the hospital stay.

\section{Clinical illustration}

Mr. G, 52 years old, had no siblings but was in a serious relationship for a number of years, although they lived separately. He was diagnosed with a tumour of the larynx and underwent a complete laryngectomy surgery. The first part of the post-operation went without any problems. However, Mr. G. shut himself off slowly but surely. He then refused to cooperate for the self-stoma care. As part of our reflective sessions, assumptions were made to explain the ill-being of the patient and his rejection of the self-care. One of our hypotheses was that the patient realised the upcoming difficulties that his return home implied. There were additional uncertainties regarding his relationship. These considerations led us to an interview which his partner took part in. The main topic was the return home. Mr G. openly expressed his desire to live with his partner. He also indicated that she could be in charge of his health care. His partner however opposed the idea. The situation was clearer for all parties. In the end, Mr. G. understood his position and agreed to take charge of his own stoma care.

As a result of this case study, we wondered if we could better anticipate patients' difficulties. A series of questions were raised: What are the signals for psychological distress in post-operative phases ? How can we identify them?

What information can we provide the patient and their family regarding the consequences of the surgery? How can we take into account their expectations and needs and guide them throughout the process?

This questioning was the starting point of our project.

\section{Objectives of the project}

These findings motivated us to develop a nurse consultation by focusing on the pre-operative psycho-social realities of the patient. The objective was to anticipate possible psychological and social difficulties, which may appear in the critical post-operative phase.

We conclude that taking into account the psycho-social dimensions of the patient during the preoperative nurse consultation will allow us to improve the care offer and anticipate postoperative problems and better prepare for the return home.

Our goal was to develop a frame for nursing preoperative consultation that allowed clear identification of the potential difficulties of the patient, as well as their needs and resources.

Thus, we could define tailored actions for the specific needs of the patient and start networking if required. 
In collaboration with the nursing service liaison psychiatry, we decided to restructure the existing nurse preoperative consultation, hence leaving more room for psychological and social realities of the patient and his relatives.

\section{A new guide}

In the first PNC (Preoperative Nurse Consultation), emphasis was given to the technical explanations of postoperative changes for which the patient had to get prepared.

The questions were mostly closed questions.

The new guide includes six issues addressed by nurses (see Table 1).

Table 1. Guide to the preoperative nurse consultation (PNC) "Major Intervention ENT"

Explain to the patient the purpose of the PNC

Answer questions, provide information to prepare the hospitalization because communication will be difficult after surgery and see if the patient has any special requests

\begin{tabular}{|c|c|c|}
\hline ITEMS & Questions and Themes to be addressed & Objectives \\
\hline Patient journey & $\begin{array}{l}\text { Do you have any priority before we begin? } \\
\text { How did you discover the disease? }\end{array}$ & $\begin{array}{l}\text { Check the patient's concerns and } \\
\text { perception of the disease }\end{array}$ \\
\hline $\begin{array}{l}\text { Understanding of the operation } \\
\text { and its consequences }\end{array}$ & $\begin{array}{l}\text { What do you understand of the planned surgery? } \\
\text { How do you see its consequences? }\end{array}$ & Listen and check what they understood \\
\hline \multirow{5}{*}{ Psychological state } & $\begin{array}{l}\text { Have you had other hospitalizations? } \\
\text { (in psychiatry?) }\end{array}$ & $\begin{array}{l}\text { Knowing the patient experience related to } \\
\text { other hospitalizations, anticipate possible } \\
\text { difficulties mentioned }\end{array}$ \\
\hline & $\begin{array}{l}\text { How do you feel now? (emotions experienced in } \\
\text { relation to illness, surgery, their general } \\
\text { situation) }\end{array}$ & \multirow[t]{2}{*}{$\begin{array}{l}\text { Identify the emotional state of the patient } \\
\text { Knowledge resources } \\
\text { Identify the patient's coping }\end{array}$} \\
\hline & What helps you in difficult times? & \\
\hline & $\begin{array}{l}\text { Do you smoke? (smoking cessation after } \\
\text { surgery, anatomy will be different after } \\
\text { laryngectomy) }\end{array}$ & Provide an alternative \\
\hline & $\begin{array}{l}\text { Do you regularly consume of alcohol or other } \\
\text { substances? (explaining the risk of delirium } \\
\text { tremens and the alcoholic withdrawal) }\end{array}$ & Provide an alternative \\
\hline \multirow{4}{*}{ Social environment } & $\begin{array}{l}\text { Who are the people close to you? Who can come } \\
\text { to visit you during your hospital stay? }\end{array}$ & $\begin{array}{l}\text { Knowing the context of family and } \\
\text { entourage to anticipate the result } \\
\text { Identify resource persons }\end{array}$ \\
\hline & $\begin{array}{l}\text { How do your relatives cope with the perspective } \\
\text { of your operation and its consequences? }\end{array}$ & Know the resources or help needs \\
\hline & What is your main occupation? & Knowing the patient's resources \\
\hline & $\begin{array}{l}\text { Do you foresee any changes or difficulties } \\
\text { related to work or family situation? }\end{array}$ & $\begin{array}{l}\text { Propose using the social worker as } \\
\text { needed. }\end{array}$ \\
\hline Project (s) of the patient & How do you see the future? & $\begin{array}{l}\text { Projecting the patient vision of hospital } \\
\text { stay and after anticipation of future } \\
\text { difficulties }\end{array}$ \\
\hline Conclusion of the interview & $\begin{array}{l}\text { Repeat the key elements of the discussion with } \\
\text { the patient. }\end{array}$ & Check mutual understanding. \\
\hline
\end{tabular}

\section{I mplementation}

Caregivers are trained to maintain flexibility with respect to the hierarchy of the various issues in order to be closer to the concerns of the patient and his pace. 
Example: if the patient begins the interview with emotions running high ("I am angry"), the caregiver will follow the patient and listen carefully to all his statement describing feelings. The immediate effect is the lowering of the patient's emotional level. It is imperative to a good start to the therapeutic relationship.

The patient often shows thereafter more willingness to understand the practical aspects and difficulties of the operation in the short, medium and long term.

During the interview, patients express their concerns in various ways.

Examples:

"I can't bear the pain anymore, I need immediate treatment against the pain."

"When I am upset, leave me alone for a while"

"I am very scared to manage diabetes after the operation, I have had bad experiences already."

After the consultation, the nurse writes a transmission sheet showing the different sections of the guide, added to the medical nursing file.

\section{Positive balance}

Throughout 2011, 42 patients were scheduled for a major surgery of the head and neck and attended a preoperative nurse consultation following the new guide.

Caregivers found that since the introduction of the new guide, the patients made more reports of their experiences, their feelings and concerns. The overall consideration of the patient's situation was facilitated.

As result of consultation, patient had a better understanding of the surgery and consequences. They feel taken into consideration and are more open to ask questions.

However, some caregivers also said that they were more exposed to the patient's emotional reactions or confusing statements. Caregivers found that the nurse who conducts this first consultation became a key person for the patient.

A link is created and is often maintained throughout the hospitalisation. Indeed, the patient often talks more easily about his concerns to the nurse he had seen previously during the nurse consultation, irrespective of the fact whether or not this was the referent nurse of the day.

\section{Postoperative follow - up}

Nurses easily note physical problems such as pain, risk of malnutrition, risk of delirium tremens, etc. However, the problem related to psychological and social aspects are less well documented in the files.

In some situations a specialised monitoring commences after the preoperative nurse consultation. This is conducted by other services such as social service, psychiatry link and treatment center for alcoholism (...), which seems to alleviate caregivers of such psycho-social workload.

\section{Discussion}

Generally speaking, patients' feedback is extremely positive towards nurse consultation. This is their first significant link with caregivers. Patients feel they are being listened to, are well informed and several of them noticed that requests made during the PNC were fulfilled. 
If caregivers' feedback as a whole is very positive, there are still areas of improvement and potential adaptations to implement. Following the observations made by nurses practising PNC under the new guidelines, we created a complementary technical memo for caregivers: "support tool for the PNC". The new application guide for caregivers requires more specific skills in counselling. The aim is for the caregiver to feel comfortable with this type of interview in which a lot of freedom of speech is granted to the patient.

\section{Conclusions}

Introduced in 2011, the nurse preoperative consultations helped diagnose, in a systematic manner, the concerns of patients whether physical or psychological (guilt, low self-esteem) or social, or spiritual. Internal personal resources (coping) as well as external resources were well identified and better solicited.

The nurse who performs this consultation becomes a key person for the patient. Therefore, it was decided that all nurses lead consultations. The responsibility of nursing consultations is based on the team, which allows better continuity to the project.

In the upcoming months, our efforts will be focused on the implementation of tools which take into consideration the PNC data collected throughout the patients' care.

In the same logic, we are leading a reflection on the opportunity of a nurse consultation for preparing the patient to return home and present the future care follow-up.

It is hoped that this PNC guide will evolve and take advantage of new analysis and discoveries, especially since it could easily be adapted to the specific needs of other care services. Several CHUV Lausanne University hospital services have also shown interest to use the same guide for the creation of a nurse preoperative consultation.

\section{I mproved preparation}

This consultation allowed Mr. T. to be more comfortable with what would happen to him during his hospitalisation. He better anticipated the duration of the stay in hospital:" It is a long process but I was aware of it and it helps me now see the end of it".

During the PNC, the patient's concerns were focused on the difficulty to communicate during the postoperative phase. Due to his loss of voice quality after the tracheotomy and the suffering from bilateral hypoacousia.

Being of foreign origin, the patient could not write or read French. The consultation anticipated the difficulties of communication between the patient and his family in the postoperative phase. The nurse handed him two documents with symbols for potential needs in the first weeks: need to go to the toilet, pain, etc. The team also called a caregiver speaking the patient's mother tongue. His family were active participants in the process and were given the opportunity to express the patient's his daily needs to caregivers.

\section{References}

[1] Cady J.: Laryngectomy: beyond loss of voice. Caring for the patient as a whole. Clinical Journal of Oncology Nursing. 2002; 6(6).

[2] Babin E.: La vie après la laryngectomie totale. Revue de laryngol. Oto. Rhinol. 2001; 122(5): 303-309.

[3] Stagno D., Stiefel F., Rousselle I., Guex P.: Diagnostic et traitement chez les patients souffrant de cancer. Revue Médicale Suisse , 2005. 